\title{
O QUE HÁ DE RADICAL NA TEORIA DEMOCRÁTICA CONTEMPORÂNEA Análise do debate entre ativistas e deliberativos*
}

\section{Cláudia Feres Faria}

O fim do socialismo na Europa Oriental (1989) deixou marcas consideráveis no pensamento político contemporâneo e, por consequiência, na teoria democrática (Grodnic 2005). Sob a perspectiva do "fim da história" e do triunfo do capitalismo democrático liberal, tal como praticado nos países ocidentais, a agenda teórica dos democratas radicais passou por mudanças importantes, cuja ênfase passa a ser "a radicalização da tradição democrática moderna" e não mais a idéia de substituição completa da ordem política vigente (Mouffe, 1992; Bohman, 1996).

Se, por um lado, podemos identificar na idéia de radicalização da democracia um ponto de conver-

* Agradeço os comentários feitos pelos participantes do grupo de trabalho de Teoria Política da ABCP-2008, bem como as sugestôes críticas elaboradas por dois pareceristas anônimos. Os erros remanescentes são de minha inteira responsabilidade.

Artigo recebido em novembro/2008

Aprovado em março/2010 gência desta agenda, a forma de torná-la plausível nas sociedades contemporâneas, marcadas pela complexidade, pelo pluralismo, pelos desarcordos profundos e pela crescente desigualdade, não é consensual. Enquanto autoras como Mouffe (1992, 2000), entre outras, endossam a reformulação da tradição liberal mediante $\mathrm{o}$ abandono das premissas individualistas e racionalistas, bem como da recuperação da dimensão da participação ativa e do pluralismo, autores como Cohen e Fung (2004), partindo também da defesa desta mesma tradiçãa, apóiam sua reformulação com base no aumento não só das práticas participativas, mas também das práticas deliberativas, cuja ênfase recai no debate e na discussão racional que precede e justifica as decisōes alcançadas (Habermas, 1997; Benhabib, 1996; Bohman, 1996; Dryzek, 2001; Gutmann e Thompson, 2004).

A defesa da ampliação da participação, assim como o anseio por mais deliberação não constituem novidades para a teoria política, uma vez 
que dos gregos aos liberais do século XIX tal argumento esteve sempre presente (Bohman, 1998). Entretanto, em um contexto sociopolítico radicalmente diferente, caracterizado, entre outras coisas, pela extensão universal do sufrágio e pela progressiva restrição aos espaços deliberativos (Fishkin e Luskin, 2005), o debate estabelecido no interior do campo teórico e prático dos democratas radicais em torno das possibilidades inclusivas das democracias contemporâneas constitui uma novidade que merece ser analisada.

Se, de um lado, ativistas ${ }^{1}$ e deliberativos identificam-se em relação ao endosso e, simultaneamente, aos limites da democracia liberal contemporânea, de outro, divergem quanto aos melhores mecanismos para radicalizá-la. Analisar este debate constitui objeto deste artigo.

Começaremos analisando a constituição da agenda teórica dos democratas deliberativos. Para tal, na primeira seção, buscaremos retratar os diversos significados que o termo deliberação vem assumindo. Na segunda seção, analisaremos os princípios normativos que guiam essa diversidade semântica. Mostraremos em seguida, na terceira seção, como os deliberativos, cientes que são da necessidade dos métodos convencionais de construção da decisão política - o voto, as eleiçôes, a organização da vida política em partidos, a regra da maioria etc. - nas sociedades de massa, buscam democratizar tais métodos. Na quarta seção, as críticas dos ativistas a esta agenda de pesquisa será analisada. É possível adiantar, entretanto, que elas se concentram, primordialmente, na possível ingenuidade dos deliberativos quanto às potencialidades da prática discursiva em incluir novas vozes ao processo democrático das sociedades contemporâneas (Sanders, 1997; Young, 2000, 2001a; Dryzek, 2001; Mouffe, 2000). Por fim, na seção conclusiva, buscaremos apontar, a partir do diálogo estabelecido entre deliberativos e ativistas, as possibilidades da radicalização da democracia nestas mesmas sociedades.

\section{A diversidade semântica do termo deliberação}

Tomando Jürgen Habermas como um dos principais expoentes da agenda deliberativa é pos- sível afirmar que o termo deliberação designa, para este autor, um "ato intersubjetivo de comunicação e argumentação, cujo o objetivo é alcançar um consenso sobre a solução para determinado problema social" (1997, p. 305). Para tanto, a deliberação envolve: (a) argumentação, ou seja, intercâmbio regulado de informações e de razões entre partes que introduzem e examinam criticamente propostas; (b) publicidade e inclusividade: ninguém pode, a princípio, ser excluído. Todos aqueles que são possivelmente afetados pelas decisóes devem ter chances iguais de tomarem parte de sua elaboração; (c) ausência de coerção externa: os participantes são soberanos na medida em que só se encontram vinculados aos pressupostos da comunicação e às regras procedimentais de argumentação; (d) ausência de coerção interna: cada participante tem oportunidade igual de ser ouvido, de introduzir novos tópicos, fazer propostas e contribuições, assim como de criticar aquilo que foi proposto. A tomada de posição $\mathrm{sim} /$ não é motivada somente pela força do melhor argumento; (e) acordos racionalmente motivados que podem ser, a princípio, desenvolvidos sem restrições ou retomados em qualquer momento. Não obstante, as deliberações devem ser concluídas levando em conta a decisão da maioria. Devido ao seu nexo interno com a prática deliberativa, a regra da maioria justifica o pressuposto de que a opinião da maioria pode ser considerada uma base razoável para uma prática comum, até que a minoria convença a maioria do contrário; (f) regulação de todos os assuntos tendo em vista o interesse igual de todos. Isto implica que certos temas e objetos, tradicionalmente considerados "privados", possam ser submetidos à discussão. Em particular, aquelas questôes que são publicamente relevantes, pois dizem respeito à distribuiç̧ão desigual de recursos sobre os quais depende, de fato, o exercício dos direitos de comunicação e participação; (g) extensão das deliberaçôes políticas à interpretação de necessidades e à transformação de preferências e enfoques pré-políticos. Aqui, a força consensual dos argumentos não se apóia em um acordo sobre valores previamente desenvolvidos nas tradições e formas de vida comuns. Este "procedimento ideal de deliberação e de tomada de decisão" pressupõe uma associação que concorde em regular imparcialmente as condições de vida comum 
de seus cidadãos, uma vez que aquilo que os agrupa será, em último termo, o laço lingüístico com capacidade de manter a coesão de qualquer comunidade de comunicação (Idem, pp. 305-306).

Embora Habermas tenha se baseado nas contribuições de Cohen (1989) para elaborar os elementos constitutivos da deliberação pública, o autor discorda da amplitude que Cohen atribui ao processo deliberativo. Diferentemente deste, Habermas reserva a prática discursiva para a esfera pública e para partes do sistema político, notadamente o parlamento e o poder judiciário (Habermas, 1997). Ao limitá-la a esses "espaços", sem preocupaçōes mais fáticas com a eficácia dessa prática na condução dos poderes administrativo e econômico, o autor torna-se alvo de críticas referentes ao alcance inclusivo do modelo operacional de democracia deliberativa por ele proposto (Fraser, 1996; Bohman, 1996; Cohen, 1998).

É exatamente a preocupação com a operacionalização prática da deliberação que Bohman, em seu debate com as contribuições habermasianas, redefine a deliberação como

\section{[...] uma atividade social incorporada na ação} social do diálogo. Ou seja, [o ato de] oferecer e receber razões que ocorre em um contexto social específico, em face de uma situação problemática na qual a coordenação se rompe e é retomada quando os atores são capazes de cooperar novamente (1996, p. 33, grifo meu).

Os objetivos do ato deliberativo não se limitam, aqui, à busca do consenso entre os pares, mas à tentativa de resolver as situações problemáticas (conflitos), restaurar a cooperaçáo entre os atores e coordenar seus resultados. Nesse sentido, para que a deliberação se desenvolva basta que os participantes reconheçam que eles contribuem e influenciam os resultados, mesmo discordando deles. O resultado de uma decisão passa a ser aceitável "quando as razões por trás dela são suficientes para motivar a cooperação de todos" (Idem, ibidem).

Diferente de Habermas (1997), Bohman considera a deliberação mais como uma forma de diálogo do que uma forma de discurso. "É por intermédio do diálogo que as capacidades para o ato deliberativo podem ser exercidas conjuntamente"
(1996, p. 32). Segundo o autor, o diálogo público é possível mesmo quando não existe acordo unânime entre os partícipes ou quando os interlocutores não se encontram face a face. Na visão de Bohman, a deliberação é mais uma atividade cooperativa e pública do que discursiva e argumentativa.

Por que o diálogo e não a discussão? Para Bohman, a análise do diálogo está interessada em como a interação pública produz os efeitos práticos nos participantes que elaboram razōes convincentes, ao passo que a análise do discurso está interessada nos argumentos e nos tipos de justificação que possam ser publicamente convincentes. ${ }^{2}$ Ademais, a versão discursiva oferecida por Habermas busca reconstruir, ainda segundo este autor, os ideais de convergência, unanimidade e imparcialidade em termos políticos. Esses ideais não são necessariamente os pressupostos da discussão democrática ou da argumentação pública (Idem, p. 34).

A explicação alternativa de Bohman - o processo dialógico - parte do pressuposto de que a publicização não consiste no conhecimento pleno de todos os interesses e de todas as razões relevantes. Ela é uma forma particular pela qual se oferecem razões e se obtêm respostas via comunicação.

Oferecer uma razão é demandar uma resposta de outros; se a audiência dessa resposta é geral e não restrita, tanto a razão, como a audiência para qual ela é dirigida podem ser consideradas públicas. Tal público se difere do coletivo na medida em que a comunicação generalizada na esfera pública não requer qualquer compartilhamento de crenças e valores de primeira ordem. [...] A esfera pública não precisa de uma consciência coletiva, nem de uma comunidade, embora ambas possam emergir da prática pública. Entretanto, para sustentar essa esfera pública e esse processo de reflexão temporalmente é necessária uma estrutura comum: uma estrutura de convençôes formal e informal, acordos e leis explícitas que tornem possível a deliberação pública. Essa própria estrutura deve ser garantida pela razão pública e deve possibilitar a própria deliberação. Para cumprir tal tarefa, ela deve estar aberta às novas razōes e revisões (Idem, p. 46). 
A mudança do discurso para o diálogo, na versão deliberativa apresentada por Bohman, já considera algumas das preocupaçōes que iremos encontrar nas críticas dos ativistas ao suposto caráter elitista da prática deliberativa. A alternativa apresentada pelo autor visa diminuir as "exigências epistêmicas" contidas no ato discursivo quando se tenta ampliar as chances de participação daqueles que desejam conformar a deliberação pública, ou seja, as chances inclusivas.

Dryzek apresenta uma outra alternativa para buscar ampliar as chances inclusivas da prática deliberativa ao defini-la como um "um tipo de comunicação que induz, de forma não coercitiva, a reflexão sobre as preferências dos atores sociais envolvidos" (2001, p. 2, grifo meu).

É neste sentido que o autor, em contraposição à Habermas, Cohen e Bohman e junto com Young e as democratas da diferença, defende não só o discursso racional como meio da deliberação autêntica, mas também outras formas de expressão como a retórica, a emoção, o humor, a fofoca e o testemunho. Dryzek acredita que tais formas podem ser indutoras de maior inclusão política. Não obstante, ainda que elas devam ser consideradas, na visão do autor a discussão racional permanece central para a democracia deliberativa, na medida em que a validade inclusiva das outras formas de comunição aludidas requer comprovação empírica.

Para assegurar a pluralidade de identidades, próprias às sociedades contemporâneas, Dryzek sugere ainda que a esfera pública seja pensada como "uma arena de contestação de discursos sobrepostos" cujo resultado no sistema político nem sempre é decisivo, mas que, em determinados momentos, faz diferença e induz mudanças no contéudo da política pública (Idem, p. 73). Dessa forma, o autor também busca oferecer uma outra resposta para a questão da deliberação como busca de consenso ou acordo unânime entre as partes.

Em Gutman e Thompson, a deliberação é definida como "o ato de justificar as decisóes tomadas pelos cidadãos e por seus representantes. O que caracteriza a deliberação é aqui a exigência por justificação que pode assumir contornos processuais e/ou substantivos" (2004, p. 3, grifo meu). Nesse sentido, estes autores estabelecem um diálogo com os procedimentalistas como Habermas e Cohen, uma vez que não endossam somente uma visão procedimental da deliberação, mas buscam reconciliá-la com uma abordagem mais substantiva. Afirmam, também, que a deliberação pode conviver com outras formas de tomada de decisões, desde que o uso dessas formas seja, em algum momento do processo deliberativo, publicamente justificado. Mas acreditam que a deliberação, comparada aos métodos agregativos de decisão, pode diminuir os efeitos discriminatórios oriundos das relaçôes de classe, gênero e raça, pois pode tornar público o uso indevido de determinados meios, como, por exemplo, poder e dinheiro. Não obstante, concordam com a sugestão dos ativistas, como veremos adiante, que algumas formas de ação pública, como a passeata e/ ou o boicote, podem se tornar mais eficientes para forçar os limites da política (Idem, pp. 65-67).

Por fim, Manin define a deliberação como "o processo de formação da vontade, o momento que precede a escolha por meio da qual os individuos ponderam soluçōes diferentes antes de chegar a uma delas". Assim, a deliberação configura, para ele, "um processo de formação das preferências mediante informaçōes" (1987, p. 345, grifos meus). A fonte da legitimidade dessas decisōes não residiria na vontade predeterminada dos indivíduos, mas no processo de formação desta mesma vontade, que é, segundo ele, a própria deliberação.

Embora Manin, assim como Cohen, tenha contribuído sobremaneira para divulgar o termo na última década do século passado (Dryzek, 2001), é possível afirmar que a forma como ele desenvolve o termo no interior da teoria democrática o distingue dos demais, notadamente J. Habermas.

Em primeiro lugar, Manin discorda, assim como Bohman, que o acordo racionalmente motivado sobre as normas morais e políticas, produzidas pela deliberação, tome a forma de um consenso unânime entre as partes envolvidas. Para ele, dada as regras procedimentais apropriadas para a deliberação, o melhor argumento é aquele que gera maior apoio e não aquele capaz de convercer todos os participantes (1987, p. 353). Segundo, ele, diferentemente de Habermas e da maior parte dos autores supracitados, na medida em que atribui aos partidos o local próprio à deliberação nas sociedades complexas, afirma que 
[...] a contribuição dos partidos para a democracia deriva do fato de que eles permitem a deliberação de todos sobre matérias já relativamente determinadas. A existência de partidos políticos é, assim, essencial para a deliberação. Os partidos enfretam-se, e o processo argumentativo é submetido ao arbítrio de todos (Idem, p. 359).

Dessa forma, embora crtiticando o pressuposto das preferências e dos interesses previamente dados, assumido pelos pluralistas tradicionais, Manin, como estes, defende as instituiçóes convencionais da democracia liberal representativa como os melhores locais para o desenvolvimento da deliberação pública. Nesse caso, ele se diferencia dos autores aqui analisados, os quais, embora não desconsiderem a representação política como mecanismo de inclusão e de tomada de decisão, não consideram os partidos um ator privilegiado, dando maior ênfase à participação extra-institucional ${ }^{3}$.

\section{Elementos constitutivos da deliberação}

Em que pese a diversidade semântica do termo deliberação, é possível afirmar que todas as concepçôes retratadas retêm, em suas elaboraçôes, os mesmos elementos constitutivos.

Desde a publicação de Legitimation crisis (1973), Habermas já ressaltava que a fonte de legitimidade de um governo se encontra no julgamento coletivo das pessoas. Uma vez que os cidadãos de uma comunidade política não devem ser tratados como objeto das decisōes, como sujeitos passivos dos governos, eles devem não só debater os diversos motivos que conformam uma decisão, mas também solicitar que seus representantes o façam. Pretende-se, assim, produzir decisōes justificadas e, ao mesmo tempo, expressar o respeito ao outro.

Como mostram Gutmann e Thompson, o respeito ao outro deriva do reconhecimento, ensejado pelo ato deliberativo, do "mérito moral presente nas exigências dos oponentes". Segundo os autores, não se trata de compatibilizar valores incompatíveis, mas ajudar os partícipes a reconhecerem o valor contido nas pretensóes dos outros (2004, p.
17). Com isso, não se espera também a formação de um consenso, mas de uma relação pautada pelo respeito mútuo.

O caráter duplamente público da justificação defendido pelos autores - ela deve ocorrer em público e não na privacidade, assim como deve ser acessível, isto é, aqueles que tomam parte desse processo devem entender o conteúdo da discussão - qualifica ainda mais a presunção de a deliberação ensejar simultaneamente a publicidade e a inclusividade. O que Gutmann e Thompson estão defendendo com a preocupação em tornar o conteúdo das discussōes acessíveis é que todos os envolvidos sejam capazes de tomar parte do processo em curso. Neste caso, mesmo que o entendimento sobre as questóes em pauta não seja completo, presume-se que a deliberação possa induzir uma compreensão individual e coletiva maior em função da disseminação pública de informaçōes acerca do problema em debate.

Esta é considerada uma das funções da esfera pública habermasiana que, como se sabe, deve atuar como uma caixa de ressonância dos problemas tematizados na sociedade, possibilitando a circulação de diferentes pontos de vistas sobre questōes relevantes para a coletividade.

O controle público também deriva desta exigência de justificação das açôes para o público envolvido. Segundo Bohamn, todas as vezes que as expectativas e/ou a coordenação da ação quebram, espera-se uma justificação pública e uma prestação de contas caso se queira reconstituir a relação em desenvolvimento. Mas, novamente, não basta só prestar contas, a justificação pública precisa ser inteligível e capaz de responder às objeçôes dos outros; caso contrário, o espaço público corre o risco de se esvaziar (1996, p. 50).

No que diz respeito à justiça, neste caso procedimental, afirma-se que a deliberação, mesmo sob condiçôes injustas, contribui mais para a eliminação das mesmas do que outras formas de comunicação. Ao publicizar tais situações, a deliberação pode vir a constranger as açôes dos grupos socialmente dominantes, ao passo que determinados tipos de negociação, como a barganha, por exemplo, tendem a reproduzir as desigualdades em jogo (Dryzek, 2001). 


\section{Relação entre deliberação e representação}

De uma forma geral, os deliberativos aqui analisados aceitam que a maioria das decisões democráticas sejam tomadas por representantes, mas defendem formas alternativas de participação popular que melhorem a qualidade da deliberação e a justiça da representação. Dado que os mecanismos formais de tomada de decisão não exaurem as possibilidades democráticas nas sociedades complexas e pluralistas e nem resolvem problemas que supõem resolver - melhorar a qualidade da opinião pública, coordenar as diferentes preferências, oferecer chances iguais de vocalização das mesmas -, os deliberativos apostam na pluralidade de espaços deliberativos com graus de influência diferenciados no sentido de que possam contribuir para qualificar a representação.

Dessa forma, parafraseando Miguel (2003), é possível afirmar que uma terceira dimensão da representação emerge para além da autorização e do controle público vertical. Ela reside exatamente na possibilidade de publicização de novos temas por tais esferas múltiplas. ${ }^{4}$ Ademais, esses espaços têm o potencial de informar os representantes que, espera-se, "não decidam somente entre si, mas que comuniquem e ouçam seus representados por outros meios que não somente o voto ocasional" (Gutman e Thompson, 2004, p. 30).

A participação nos espaços deliberativos seria, assim, indutora não só de mais oportunidades para os cidadãos tomarem parte da deliberação, mas também do desenvolvimento das virtudes da cidadania, incentivando-os a considerarem questôes políticas de maneira mais pública. Ou seja, ao defederem a autonomia política com base na troca de razóes, os deliberativos não esperam que os grupos de interesses desapareçam como forças políticas, mas pretendem tão-somente assegurar que o argumento político e os apelos por interesses sejam estruturados de forma mais pública, levando em consideração valores como justiça, igualdade e generalização dos ganhos. Quando tais valores são levados a sério pelos cidadãos, as decisões deixam de ser somente produtos do poder e dos interesses e passam, segundo Cohen e Fung, a serem vistas também, por estes mesmos cidadãos, como um guia de suas próprias razôes, independentemente da existência de desacordos entre eles (2004, p. 26).

\section{Limites inclusivos da democracia deliberativa}

Um dos campos comuns de crítica à teroria deliberativa encontra-se entre autores que compartilham uma visão agregativa da democracia, cuja ênfase recai nos interesses dos indivíduos e na forma de agregá-los com o objetivo de alcançar decisōes vinculantes. ${ }^{5}$ Tornou-se conhecida a coletânea organizada por Elster em que o autor, entre outros, afirma, em debate com as formulações de Habermas $(1987,1996)$, que "a tomada de decisão coletiva por indivíduos livres, iguais e racionais não necessariamente precisa tomar a forma de deliberação" (1998, p. 111). Existem outras maneiras de se alcançar tais decisões, como a barganha e o voto, cujo uso depende do fator "tempo", crucial no processo de constituição de decisões vinculantes. Além do constrangimento temporal, este autor considera a barganha e o voto, sem comunicação prévia, formas superiores de se alcançar decisōes coletivas quando comparadas ao debate nos fóruns públicos. Para ele, a publicização, tão enfatizada pelos democratas deliberativos, no processo de deliberação constitui tão-somente uma

[...] força cilizatória da hipocrisia, uma vez que induz e constrange os interlocutores a esconderem seus motivos básicos (a maximização de seus interesses privados), embora não os eliminem. Assim, a força civilizatória decorrente da publicização, ao mascarar os interesses privados como se fossem públicos, ofereceria um argumento second-best para a deliberação (Idem, ibidem).

Pretende-se aqui explorar, entretanto, um outro conjunto de críticas, qual seja, aquelas elaboradas pelos autores que se auto-intitulam democratas radicais, ou seja, que defendem a ampliação da inclusão política, seja por meio da presença ativa de grupos e movimentos nos processos decisórios das sociedades contemporâneas, seja por meios deliberativos, requerendo para tal uma "soberania popular 
desubstancializada" como sugere Habermas (1997). Tal "campo" tem como pais inspiradores um conjunto de autores que vão de Aristóteles e Rousseau a Dewey e Arendt (Bohamn, 1998, p. 401; Cohen e Fung, 2004, p. 25).

Uma das críticas que conformam este "campo" diz respeito ao suposto estreitamento da agenda de pesquisa dos democratas radicais em decorrência de uma possível acomodação aos fatos da realidade social, principalmente o argumento da complexidade social próprio às sociedades contemporâneas (McCarthy, 1985).

Ao contrário dos democratas agregativos, alguns desses autores veêm com bons olhos "o ideal da democracia baseada na discussão" (Young, 2001a; Mouffe, 2000), mas apontam um conjunto de limitaçōes. Uma delas diz respeito ao arrefecimento do potencial crítico da própria teoria.

Para alguns autores, os deliberativos, embora não descartem por completo a perspectiva participativa, ou seja, aquela centrada na trasformação da sociedade e de suas instituiçóes por meio da participação ativa e direta dos cidadãos em diversos locais (Pateman, 1986; Macpherson, 1987), não a endossam mais em defesa de uma abordagem considerada reformista, que busca mostrar os potenciais e os limites do emprego público e autônomo da razão prática. O objetivo é promover iniciativas democráticas, dentro ou fora do Estado, que tornem os procedimentos usuais de tomada de decisão mais abertos à interferência do público por meio da razão pública (Hauptmann, 2000). Essa defesa tem como pano de fundo a consideração dos fatos da complexidade social e seus limites à uma participação mais ampla. Os cidadãos passam, portanto, a participar somente daquilo que os interessam em esferas públicas múltiplas e a exigir, de resto, justificativas públicas para os atos de seus representantes e/ou autoridades (Warren, 2002).

Papadopoulos e Warin (2007) argumentam, com propriedade, que, embora participativos e deliberativos almejem melhorar a qualidade da vida pública, eles o fazem por meios diferentes. Os participativos defendem o envolvimento direto, amplo e sustentado dos cidadãos nas questôes públicas. Preocupam-se, assim, mais com a inclusão como condição para a efetividade e a legitimidade da polí- tica do que com a qualidade das razões apresentadas para justificar as preferências dos atores. Os deliberativos, por sua vez, estão mais preocupados com a qualidade da discussão e da interação que irão gerar as escolhas políticas (pp. 450-451). Cohen e Fung (2004), assim como Fishkin (1991), identificam uma tensão entre participação e deliberação. Segundo os autores, melhorar a qualidade da deliberação e expandir a participação constitui objetivos contraditórios. Passeatas, demonstraçōes, referendos, recall etc. são mecanismos que promovem a participação ampla, mas não a deliberação. Ao mesmo tempo, fóruns menores são mais propícios à deliberação, mas operam à custa do insulamento do público geral (Cohen e Fung, 2004, pp. 26-27).

Sanders (1997), Gould (1996) e Young (2001a), entre outras, identificam na exclusão política uma das principais limitaçóes da democracia deliberativa. Mas, não se trata de desconsiderar os fatos da complexidade social e advogar pela extensão da participação, mas de criticar a exclusão de uma série de vozes em função da defesa de um tipo particular de interação política - a deliberação - supostamente racional e neutra (Dryzek, 2001, p. 58). Por isto Young (2001b) sugere outras formas de expressão - a saudação, a narrativa, a retórica, o testemunho - bem como formas de ação direta - o boicote, a demostração pública, as passeatas - para se contrapor ao discurso racional e supostamente neutro, próprio do ato deliberativo. ${ }^{6}$

Young (2001b), ao estabelecer um diálogo entre os democratas ativistas - entre os quais ela se inclui - e os democratas deliberativos, ressalta quatro diferentes críticas à teoria deliberativa que resume a agenda crítica dos autores supracitados: (1) os procedimentos deliberativos são excludentes; (2) o pressuposto da inclusão formal não é suficiente; (3) as alternativas são limitadas; e (4) a deliberação baseia-se em um discurso hegemônico.

Em geral, a autora afirma que a recomendação dos deliberativos para que os cidadãos engajem em uma discussão racional e repeitosa com outros que eles discordam é, no mínimo, ingênua e ideal. No mundo real, as deliberações - discussão e decisão - ocorrem às portas fechadas, entre elites que representam segmentos estruturalmente dominantes, possuindo, assim, grande influência sobre o proces- 
so discurssivo e as decisões alcançadas. Dessa forma, defendem os ativistas, a promoção da justiça social não pode prescindir da atividade de oposição crítica. Mais do que o acordo entre aqueles que apoiam as estruturas de poder existentes é necessário confrontá-los em espaços públicos através de manifestações públicas, como passeatas, boicote e outras açôes diretas (Idem, p. 672).

Ademais, em sociedades estruturadas por desiguladades sociais e econômicas profundas, os processos deliberativos, formalmente inclusivos, sofrerão destas mesmas tendências e serão comprometidos pela ação de atores que dominarão tanto os procedimentos como os espaços deliberativos com seus próprios interesses, embora utilizem argumentos racionais e se disponibilizem a entrar no debate. Dessa forma, os ativistas prescrevem a não participação nestes espaços com o objetivo de não legitimá-los e, defendem o protesto e a crítica ao processo em curso que envolve desde a elaboração da agenda até os resultados finais dos fóruns públicos discurssivos (Idem, p. 679).

Ainda segundo Young, os defensores dos procedimentos deliberativos parecem não atentar para os constrangimentos estruturais e institucionais que limitam as alternativas políticas nas democracias reais. Na maior parte do tempo, afirma a autora, os políticos operam sobre alternativas limitadas que são produzidas e apoiadas pela desigualdade estrutural.

Por fim, uma última limitação apontada pelos ativistas e também derivada da desigualdade estrutural diz respeito à influência de um mesmo tipo de discurso, o hegemônico, nos espaços deliberativos. Se tais discursos estruturam o proceso deliberativo, o acordo alcançado não pode ser considerado genuinamente livre dado que é, pelo menos parcialmente, condicionado por eles. Se esses discursos estão contaminados por relaçôes de poder injustas, os acordos atingidos irão mascarar exatamente tais relações. O prognóstico, portanto, é desafiá-los, bem como os processo deliberativos nos quais eles ocorrem. Isto se realizaria por meios não discurssivos, ou seja, por outros formas de expressão e ação que não a argumentação (Idem, p. 687).

O que Young $(2001 \mathrm{a}, 2001 \mathrm{~b})$ defende com as críticas descritas é mudar "da simples disposição de dar e ouvir razões para uma compreensão mais am- pla da geração e influência da opinião pública. [...] Para isto, além do engajamento na discussão com os outros, é necessário também protestar e engajarse em ações diretas". Em que pese a tensão existente entre essas duas formas de ação, a autora assegura que elas podem ocorrer juntas e promover uma opinião pública mais crítica, conformando, assim, um outro campo da democracia radical denominado por Fung (2005) de ativistas deliberativos. Tal perspectiva ocorrerá sempre que "a força do melhor argumento" não for suficiente para estabelecer uma deliberação justa e inclusiva.

\section{À guisa de conclusão}

Como apontado na introdução deste artigo, os democratas radicais buscam, antes de mais nada, democratizar a democracia liberal, mesmo que sacrifiquem o ideal transformador das sociedades liberais e dos princípios que a guiam. Os acontecimentos do fim do século passado contribuíram em muito para a mudança nesta agenda teórica.

Tal constatação não nos exime de questionar até que ponto o diálogo aqui retratado entre deliberativos e ativistas ajudam a moldar os objetivos almejados pelos democratas radicais. Começaremos por afirmar que os deliberativos contribuem para esta agenda ao buscarem superar os limites da tradição liberal em pelo menos três campos: o controle público mais autêntico, a ampliação da igualdade formal e a autonomia política (Cohen e Fung, 2004). Os ativistas, por sua vez, ao denuciarem os possíveis vícios elitistas da democracia deliberativa recuperam a dimensão social e participativa que pode estar ausente na discussão sobre a deliberação. Assim, as dimensões deliberativa e participativa da democracia, embora partindo de pressupostos diferentes, como já apontado, oferecem aos cidadãos, que assim desejarem, oportunidades adicionais de treinamento e aprendizado político, capacitandoos a julgarem com mais propriedade os méritos das leis e das políticas produzidas. Ademais, tal perspectiva, ao defender simultaneamente a deliberação e a participação em espaços públicos formais e informais, impactam positivamente a questão da igualdade formal. Ao defender que a legitimidade 
das leis e da política deriva da "força do melhor argumento" e não do status social dos partícipes na confecção das mesmas, os democratas radicais estão propondo uma prática social que poderá nos sevir de escala comparativa para julgar em que medida a participação está assentada em hieraquias sociais e políticas dadas ou na constestação de um público organizado em bases sociais mais amplas do que aquelas promovidas pela força do dinheiro e do poder. Por fim, ao elaborarem razōes e justificativas para soluçôes de problemas comuns, os cidadãos participantes apropriar-se-iam destas mesmas leis e das políticas que os vinculam. Se é verdade que as críticas dos ativistas fazem sentido, principalmente aquelas derivadas das desigualdades estruturais que podem resultar no "elitismo cognitivo", sua solução não precisa prescindir da deliberação, mas pode ser encontrada em políticas que envolvam tanto a dimensão participativa como a deliberativa, uma vez que a própria forma de decidir sobre como utilizar tais dimensóes deve estar assentada em meios discursivos. Tal como Chambers (2003) apontou em relação às escolhas sobre diferentes formas de comunicação a serem utilizadas em diferentes contextos sociais e políticos, aqui, também, os tipos de atuação dos democratas radicais podem ser definidos mediante o debate entre as partes envolvidas. A opção pelo metódo discursivo é considerada prioritária, mas, uma vez que as condiçōes ou os oponentes o rejeitam - seus procedimentos e os valores nele contidos -, é possível recorrer a outras formas de ação. Não obstante, qualquer que seja a escolha é fundamental, a meu ver, que ela seja guiada pelo princípio da justificação pública, possibilitando, assim, resgatar parte do ideal deliberativo mesmo quando as circunstâncias lhes forem hostis.

\section{Notas}

1 Seguindo a definição de Mansbridge, ativistas são aqueles que participam da vida pública para além dos momentos eleitorais. Aqueles que se identificam com um movimento social, que se envolvem com as suas causas e que os apóiam efetivamente (1990, p. 229).

2 A distinção entre diálogo e discurso separa a visão dialógica de Bohman da explicação discursiva de Haber- mas da política deliberativa: para Bohman, o discurso demanda mais que o diálogo, pressupondo acordos unânimes sobre regras básicas e padrōes de justificação racional e, assim, só se torna aberto, em princípio, quando os pressupostos requeridos para a participação ativa dos cidadãos sejam muito altos. Já o diálogo não requer expertise epistêmica específica, tornando-se aberto a todos os cidadãos que desejam formatar o resultado da deliberação (1996, p. 57).

3 Plotke (1997), assim como Urbinatti (2006), oferece uma vinculação interessante entre práticas sociais e instituições ao repensar a representação como um conceito relacional que vai muito além da representação eleitoral.

4 Seguindo Dryzek (2001, 2006) e Benhabib (1996), esta é uma justificativa plausível para não abordarmos neste artigo autores como J. Rawls ou B. Arkeman, mesmo reconhecendo a centralidade deles na discussão sobre deliberação pública. Ou seja, a deliberação guiada pelo uso público da razão ocorre, para estes autores, em espaços sociais restritos, preferencialmente nas instituições do governo, sobretudo no Legislativo e no Judiciário. Somente em ocasiões particulares tais fronteiras serão extrapoladas. É possível chamar atenção ainda para o fato de que Rawls desconsidera o aspecto interativo (intersubjetivo) da deliberação, sendo a razão pública alcançada por meio de uma reflexão estritamente individual.

5 Enquanto a versão agregativa da democracia busca formas de decisão eficientes que retratem a agregação de interesses e preferências individuais que são privadamente formadas, a versão deliberativa da democracia preocupa-se, como vimos, com a autenticidade e com a justificação das decisões por meio de razões. Mas, como lembra Araújo, "não são quaisquer razões, mas aquelas que fundamentam a decisão no bem comum". Para tal, é necessário que os atores se comuniquem, estabelecendo uma interação que não busca apenas tornar público seus interesses, mas também obter um entendimento mútuo (2004, p. 160). Nesse sentido, a racionalidade própria à versão deliberativa de democracia é a discursiva, própria ao fórum, e não a racionalidade estratégica, própria ao mercado. A crítica dos deliberativos ao pluralismo competitivo reside no fato de essa perspectiva não atentar para tal diferença (Bohman, 1998, p. 400).

6 Young parece não atentar para o fato de que tais formas de comunicação também podem gerar assimetrias e exclusões entre os atores, podendo bloquear a própria interação. 


\section{BIBLIOGRAFIA}

ALVAREZ, Sônia; DAGNINO, Evelina \& ESCOBAR, Arthuro. (eds.) (1998), Cultures of politics. Politics of cultures. Boulder, Westview Press.

ARAUJO, Cícero. (2004), "Razão pública, bem comum e decisão democrática", in Vera S. P. Coelho e M. Nobre (orgs.), Participação e deliberação. São Paulo, Editora 34.

AVRITZER, Leonardo. (2002), Democracy and the public space in Latin America. Nova York, Princeton University Press.

BENHABIB, Sheila (ed.). (1996), Democracy and sifference. Nova York, Princeton University Press

BOHMAN, James \& REHG, Willian. (1997), Deliberative democracy. Cambridge, MIT Press

BOHMAN, James. (1996), Public deliberation: pluralism, complexity and democracy. Cambridge, MIT Press.

. (1998). "Survey article: the coming age of deliberative democracy". The Journal of Political Philosophy, 6 (4): 400-425.

CHAMBERS, Simone. (2003), "Deliberative democratic theory". Annual Review of Political Science, 6: 307-326.

COHEN, Jean \& ARATO, Andrew. (1992), Civil society and political theory. Cambridge, MIT Press.

COHEN, Joshua \& SABEL, Charles. (1997), "Directly-deliberative poyarchy". European Law Journal, 3 (4) : 313-416.

COHEN, Joshua. (1989), "Deliberation and democratic legitimacy”, in A. Hamlin e P. Pettit (eds.), The good polity. Oxford, Blackwell Publishers.

COHEN, Joshua. (1998), "Reflections on Habermas on democracy". Ratio Juris, 12 (4): 385416.

COHEN, Joshua \& FUNG, Archon. (2004), "Radical democracy". Swiss Journal of Political Science, pp. 23-46.

DAGNINO, Evelina (org.). (2002), Sociedade civil e espaços públicos no Brasil. Rio de Janeira, Paz e Terra.

DAHL, Robert. (2000), On democracy. New Haven, Yale University Press.
DRYZEK, John S. (2001), Deliberative democracy and beyond. Oxford, Oxford University Press.

DRYZEK, John S. \& NIEMEYER, Simon. (2006), "Reconciling pluralism and consensus as political ideals". American Journal of Political Science, 50 (3): 634-649.

ELSTER, John (ed.). (1998), Deliberative democracy. Cambridge, Cambridge University Press.

FARIA, Cláudia. F. (2000), "Democracia deliberativa: Habermas, Cohen e Bohman”. Revista Lua Nova, 50: 48-67.

FISHKIN, James. S. \& LUSKIN, Robert C. (2005), "Experimenting with a democratic ideal: deliberative polling and public opinion". Acta Politica, 40: 284-298.

FRAZER, Nancy. (1996), "Rethinking the public sphere: a contribution to the critque of actually existing democracy", in C. Calhoun (ed.), Habermas and the public sphere. Cambridge, MIT Press.

FUNG, Archon. (2005), "Deliberation before the revolution: toward an ethics of deliberative democracy in an unjust world". Political Theory, 397-419.

GOULD, C. Carol. (2006), "Diversity and democracy: representing differences", in Seyla Benhabib (ed.), Democracy and difference, Princeton, Princeton University Press.

GRODNICK, Stephen. (2005), "Rediscovering radical democracy in Habermas's Between Facts and Norms". Constellations, 12 (3).

GUTMANN, Amy \& THOMPSON, Dennis. (2004), Why deliberative democracy? Princeton, Princeton University Press.

HABERMAS, Jürgen (1975), Legitimation crisis. Boston, Beacon Press.

HABERMAS, Jürgen. (1984), Mudança estrutural da esfera pública. Rio de Janeiro, Tempo Brasileiro.

. (1989), The theory of communicative action. Boston, Beacon Press, vols. 1 e 2.

(1997), Between facts and norms. Londres, Polity Press.

. (2005), "Concluding comments on empirical approaches to deliberative politics". Acta Politica, 40: 384-392. 
HAUPTMANN, Emily. (2000), "Can less be more? Leftist deliberative democrats'critique participatory democracy”. Polity, 33 (3): 397-421.

KNIGHT, James \& JOHNSON, Jack. (1994), "Agregation and deliberation: on the possibility of democratic legitimacy". Political Theory, 22 (2): 277-296.

MANIN, Bernard. (1987), "On legitimacy and political deliberation". Political Theory, 15: 338368.

MANSBRIDGE, Janes (ed.). (1990), Beyond selfinterest. Chicago, The University of Chicago Press.

McCARTHY, Thomas. (1985), "Complexity and democracy or the seducements of systems theory". New German Critique, 35.

MIGUEL, Luiz. F. (2003), "Representação política em 3-D. Elementos para uma teoria ampliada da representação política”. Revista Brasileira de Ciências Sociais, 18 (51): 26-39.

MOUFFE, Chantal (ed. ). (1992), Dimensions of radical democracy: pluralism, citizenship, community. Londres, Verso.

. (2000), "Deliberative democracy or agonistic pluralism”. Political Science Series, 72: $1-17$.

PAPADOPOULOS, Yannis \& WARIN, Philippe. (2007), "Are innovative, participatory, and deliberative procederus in policy making democratic and effective?". European Journal of Political Research, 46: 445-472.

PATEMAN, Carole. (1992) Participação e teoria democrática. Rio de Janeiro, Paz e Terra.

PEREIRA, Marcus A. G. (2007), "Modelos democráticos deliberativos e particpativos: similitudes, diferenças e desafios", in E. Dagnino e L. Tatagiba, Democracia, sociedade civil e participação. Chapecó, Argos.

PLOTKE, David. (1997), "Representation is democracy". Constellations, 4 (1): 19-34.

PHILLIPS, Anny. (1995), The politics of presence. Oxford, Clarendon Press.

SANDERS, Lynn. (1997), "Against d". Political Theory, 25 (3).

URBINATI, Nadia. (2006), "O que torna a representação democrática?”. Revista Lua Nova, 67: 191-228.
YOUNG, Iris M. (2001a), "Comunicação e o outro: além da democracia deliberativa”, in J. Souza. (org.), Democracia hoje: novos desafios para a teoria democrática contemporânea. Brasília, Editora da Universidade de Brasília. . (2000), Inclusion and democracy. Oxford, Oxford University Press. . (2001b), "Activists challenge deliberative democracy". Political Theory, 29 (2): 670690.

WARREN, Mark. (2002), "What can democratic participation mean today?". Political Theory, 30 (5): 677-701. 


\section{O QUE HÁ DE RADICAL NA TEORIA DEMOCRÁTICA CONTEMPORÂNEA: ANÁLISE DO DEBATE ENTRE ATIVISTAS E DELIBERATIVOS}

\section{Cláudia Feres Faria}

Palavras-chave: Democracia radical; Participação; Deliberação; Inclusão política.

Este artigo analisa o debate estruturado no interior do campo teórico dos democratas radicais em torno das possibilidades inclusivas das democracias contemporâneas. Se, de um lado, é possível afirmar que ativistas e deliberativos se identificam em relação ao endosso e, simultaneamente, aos limites da democracia liberal contemporânea, de outro, é patente que eles divergem quanto aos melhores mecanismos para radicalizá-la. Embora a defesa da ampliação da participação, assim como o anseio por mais deliberação não constituam uma novidade para a teoria social e política; em um contexto sociopolítico radicalmente diferente, marcado pela extensão universal do sufrágio, pela presença crescente de desarcordos profundos e pela progressiva restrição aos espaços deliberativos, tal debate configura-se uma novidade que merece ser analisada.

\section{WHAT IS RADICAL IN CONTEMPORARY DEMOCRACY? THE DEBATE BETWEEN ACTIVISTS AND DELIBERATIVE DEMOCRATS.}

\section{Cláudia Feres Faria}

Keywords: Modern political theory; Radical democracy; Participation; Deliberative democracy; Political inclusion.

This paper analyzes the debate on inclusive potentials of contemporary democracies, according to the theoretical approach of radical democracy. On the one hand, activists and deliberative democrats concur in supporting liberal democracies and pointing its limitations; on the other hand, they disagree on mechanisms to radicalize it. Although since the Greeks there has been support in social and political theory to the extension of participation and to more deliberation (Bohman, 1998), the present sociopolitical context changes the nature of this debate. The contemporary debates take place within a framework of universal suffrage, a reality of growing deep disagreements and increasing restriction of deliberative spaces. This new context reshapes the debates and this paper analyzes the new terms.

\section{QU'Y-A-T-IL DE RADICAL DANS LA THÉORIE DÉMOCRATIQUE CONTEMPORRAINE: ANALYSE DU DÉBAT ENTRE ACTIVISTES ET DÉLIBÉRATIFS}

\section{Cláudia Feres Faria}

Mots-clés: Démocratie radicale; Participation; Délibération; Inclusion politique.

Cet article analyse le débat structuré à l'intérieur du champ théorique des démocrates radicaux sur les possibilités inclusives des démocraties contemporraines. Si, d'un côté, il est possible d'affirmer que les activistes et les délibératifs s'identifient par rapport à l'endossement et, simultanément, aux limites de la démocratie libérale contemporraine, d'un autre, il reste évident qu'ils divergent quant aux meilleurs mécanismes pour la radicaliser. Malgré le fait que la défense de l'élargissement de la participation et le souhait pour davantage de délibération ne constituent pas une nouveauté pour la théorie sociale et politique, nous démontrons que dans un contexte sociopolitique radicalement différent, marqué par l'extension universelle du suffrage, par la présence croissante de désacords profonds et par la progressive restriction aux espaces délibératifs, un tel débat se configure comme une nouveauté qui mérite d'être analysée. 